\title{
The research Status of Steel Reinforced Recycled Concrete
}

\author{
Jiang $\mathrm{ZHU}{ }^{1, a}$, Xiao LIU $\mathrm{L}^{1, \mathrm{~b}^{\star}}$ \\ ${ }^{1}$ Institute of Architecture and Engineering of Shenyang University, Liaoning, Shenyang, China \\ az-hujiang@163.com, bliuxiao19740701@163.com
}

${ }^{*}$ Corresponding author

Keywords: Steel Reinforced Recycled Concrete, Recycled Concrete, Substitution Rate, Component, Research Status.

\begin{abstract}
Steel reinforced recycled concrete as a kind of new environmental protection structure. The steel is arranged on the recycled concrete can make up for the defect of recycled concrete and can improve the loading ability of components. It has good mechanical properties so that attracted more and more attention in the field of engineering. This paper introduced the research status of steel reinforced recycled concrete structure in recent years, and analyzed the trend of the research of steel reinforced recycled concrete in the future.
\end{abstract}

\section{Introduction}

With the acceleration of the urbanization process of human society so that all kinds of building materials is applied more and more widely, especially the using amount of concrete had increased greatly, which will increase the consumption amount of the non-renewable natural resources such as sand, stone and so on. This phenomenon has draw further apart with the sustainable development strategy. Meanwhile, the urban public and civil buildings and municipal facilities renewal, transformation and construction makes a lot of concrete was dismantled and the collapse of buildings caused by the natural disasters and so on, which caused the formation of incredible amount of architectural garbage, its number has accounted for almost $30 \% \sim 40 \%$ of the city garbage[1]. As shown in the Fig.1.
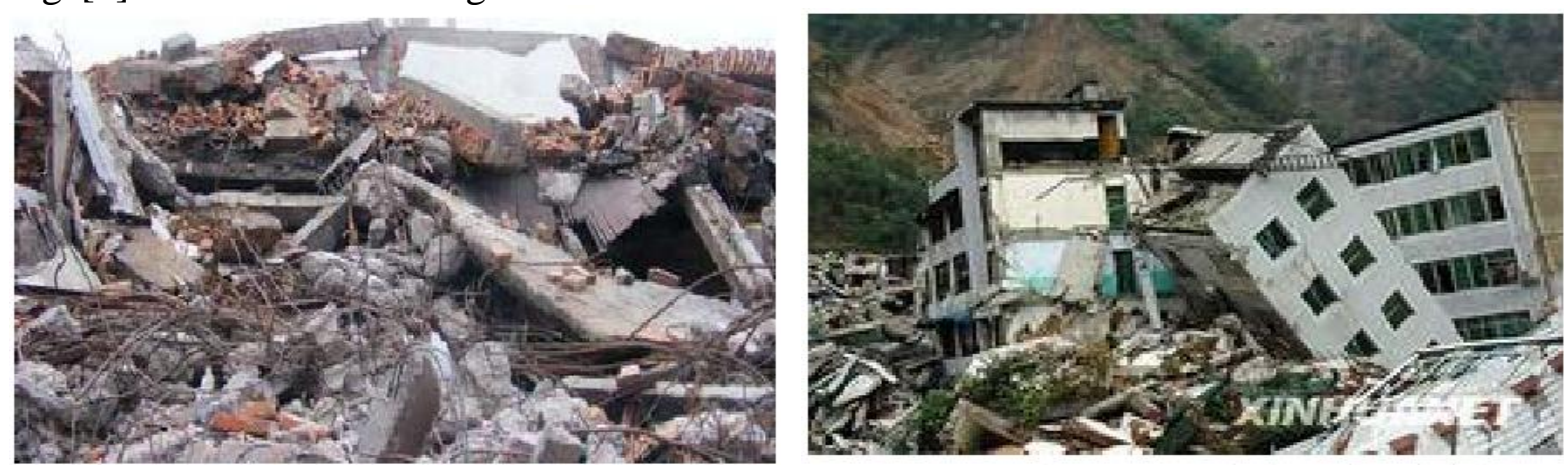

(a)The construction waste generated by city demolition; (b) The construction waste generated by the Wenchuan earthquake in 2008 .
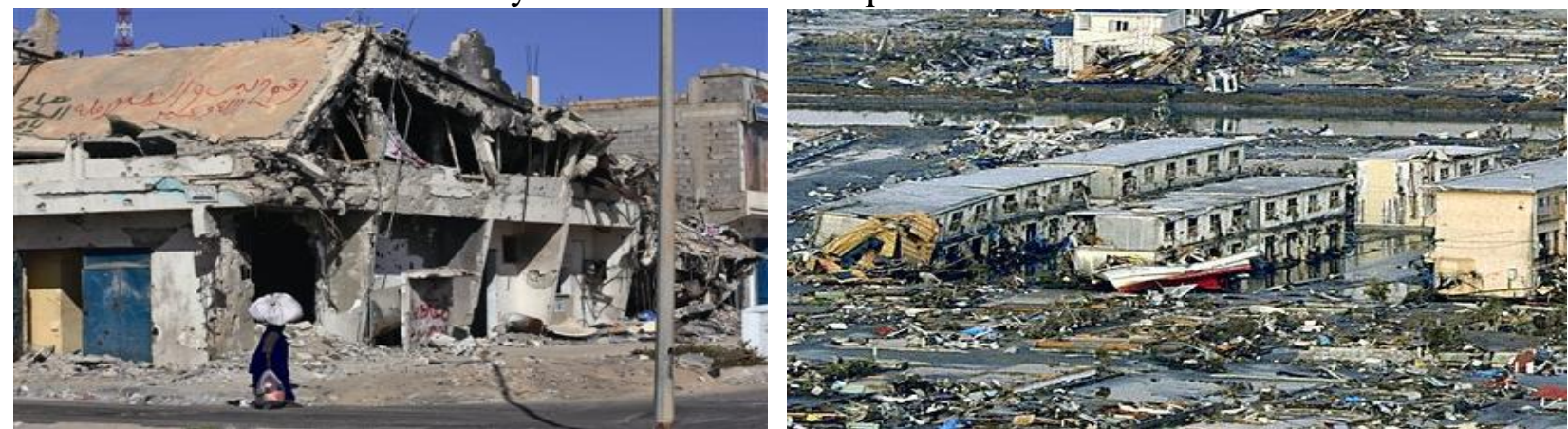

(c) The construction waste generated by the Libya war; (d)The construction waste generated by the Japan tsunami in 2011.

Fig.1 The construction waste generated by the various causes 
We must pay attention to the use of the recycled concrete to solve the problems above because its influence was serious. The domestic and foreign experts put forward the concept of recycled concrete. Recycled concrete as a kind of green material can reduce the consumption of natural sand in construction industry, slow down the pressure of the lack of resource; on the other hand, it can solve the difficult problem of disposing waste concrete. The research and development of recycled concrete has been paid high attention by many developed countries, and has become a major issue of common research in developed countries, some countries have adopted legislation to ensure the development of recycled concrete's study and application [2].

\section{The Research Status of the Structure of Steel Reinforced Recycled Concrete}

Steel reinforced recycled concrete structure is equivalent to steel structure of outsourcing concrete structure, this makes the concrete is the force component is a protective layer of steel, which makes the fire resistance and durability of steel can be improved, meanwhile, it can improve the most deadly two major defects of steel structure so that the safety performance of the structure improved at the same time. At the same time type steel concrete encased binding in the built-in type steel, can effectively prevent the local and overall buckling of steel, a steel framework without the need for stability calculation, also do not need to take special measures to improve the structural component stiffness and stability.

Zhang Wei[3], Guo Pengye[4] has done the axial pressure, small eccentric compression and large eccentric compression test of the different substitution rate and different steel ratio of recycled steel concrete columns respectively. The research results show that: both the axial compression or bias of component, damage process experienced elastic, elastic-plastic and plastic section three stages; recycled aggregate replacement rate enhancement may result in the decrease of loading capacity; the increase of eccentricity will cause the load-carrying capacity decrease; the bearing capacity of the steel ratio of ascension to make steel recycled concrete members get promotion; steel ratio in the same level, the increase of eccentricity will cause the reduction of bearing capacity of member.

Zhang Jie[5]has done the finite element simulation of the under low cyclic loading hysteretic curve of steel reinforced recycled concrete column. The research results show that: With the substitution rate become larger, the hysteretic curve of column become more full, its shape is typesrhomboid. The increase of axial load ratio will lead the structure's strength decline curve becomes steeper, limit deformation smaller after the peak load. Xue Jianyang, Ma Hui[6] has done the theoretical study on the minimum protective layer thickness of steel reinforced recycled concrete, gives a method to select the value of the minimum protective layer thickness of steel reinforced recycled concrete column.

Wang Yuncheng[7] has done the experiment which was conducted to study the compression ratio and ductility of steel reinforced recycled concrete column. The experiment selected the axial compression ratio, stirrup ratio and replacement ratio of recycled concrete as variable. The experimental results show that: axial compression ratio is inversely proportional to the ductility of columns, increasing stirrup ratio can improve the ductility of the column at some extent, and substitution rate increases will lead to the decrease in the ductility of the columns. At the same time, the formula of the limit axial compression ratio of column has been deducted based on the limit failure state.

Ma Hui[8] has done the study on the seismic behavior of steel reinforced recycled concrete columns. Investigate the recycled coarse aggregate replacement rate, the shear span ratio, the axial compression ratio and stirrup ratio whose influence on the performance of steel reinforced recycled concrete columns. The test showed that: the recycled coarse aggregate replacement rate increases so that the seismic behavior of the columns to reduce; Effect of shear span ratio on the seismic performance of the columns is larger, in the practical application should control the shear span ratio is greater than 2, to avoid the phenomenon of short column, which makes the column ductility damage; the increase of axial load ratio will reduce the seismic performance of steel under cyclic loading; the stirrup ratio increases can effectively improve the anti-seismic ability of the component. 
The test and software simulation results show that the influence factors of steel reinforced recycled concrete columns bearing capacity are recycled coarse aggregate replacement ratio, steel ratio, eccentric ratio, and axial compression ratio. The damage process of steel reinforced recycled concrete columns and ordinary steel reinforced concrete columns is basically similar, both of them will experience elastic, elastic-plastic and plastic three stages, at the same time, steel reinforced concrete column destruction has certain ductility. Therefore, although the recycled concrete can lead to bearing capacity of steel reinforced concrete column decreases, but as a form of column members, steel reinforced concrete column can be safely applied to practical project.

Liao Xingnan[9] has finished the finite element analysis for the mechanical performance of steel concrete composite beam. The simulation results show that the replacement ratio of recycled coarse aggregate has little effect on the increase of shear capacity of beam; shear span ratio increases will lead to composite beams shear carrying capacity reduction; and lifting the recycled concrete strength grade can improve the shear ability composite beams. At the same time, the replacement ratio of recycled coarse aggregate and the recycled concrete strength grade have little effect on the flexural capacity of the composite beam.

Xue Zhisheng[10] has done the study on the flexural behavior of steel reinforced recycled concrete beams. By changing the replacement ratio of recycled coarse aggregate and the reinforcement ratio of tensile reinforcement to study on the factors of bearing capacity of steel reinforced recycled concrete composite beams. The research results show that: as the influencing factors of bearing capacity of ordinary steel reinforced concrete beam, the reinforcement ratio of tensile steel is the main factor affecting the steel reinforced recycled concrete bearing capacity; and the replacement ratio of coarse aggregate have little influence on the bearing capacity of steel recycled concrete beams.

Xue Jianyang, Wang Xiuzhen[11] has done the study on the shear behavior of steel reinforced recycled concrete beams. The test selected the recycled coarse aggregate replacement ratio, shear span ratio and strength of the recycled concrete as variable. The results show that the replacement ratio of recycled coarse aggregate change has little effect on the shear bearing capacity of beam; the influence of shear span ratio on the bearing capacity is great; at the same time, the shear bearing capacity increases with the strength grade of recycled concrete.

The test and software simulation results show that the main factors affecting the steel reinforced recycled concrete beams shear capacity is the shear span ratio and recycled concrete strength grade. At the same time, the influence of the main factors of flexural performance of steel recycled concrete beams is the ratio of tensile reinforcement. Through the reasonable mixing ratio is can guarantee the strength grade of recycled concrete, therefore, this component form of steel reinforced recycled concrete beam also can be safely applied to actual project.

\section{The Research Trends of the Steel Reinforced Recycled Concrete}

In summary, steel reinforced recycled concrete is safe to be used in practical engineering, by the addition of steel, the mechanical properties of recycled concrete member increase obviously. But at the same time the recycled concrete due to residual cement mortar recycled coarse aggregate surface leads to recycled concrete strength compared with the same strength ratio concrete is lower; in addition, recycled coarse aggregate itself cracks may cause the recycled concrete new brittle failure, which restrict the application of recycled concrete in some extent. Therefore, how to handle to control impurities on the surface of recycled coarse aggregate and internal cracks are the problems that need further study.

About the research of steel reinforced recycled concrete, the present study is mainly carried out under static loading conditions, the results showed that steel reinforced recycled concrete members such as beams, columns and so on which under static loads can meet the bearing capacity, stiffness and bond performance requirements. However, its performance under the action of the dynamic force(especially seismic performance) is unknown, and domestic and international research in this area is still a blank. In addition, the performance of the nodes of steel reinforced recycled concrete in 
static and dynamic force has not been studied, in order to make the steel reinforced recycled concrete structure can be applied to seismic building structures, it is necessary to research on these two aspects.

\section{Summary}

Research shows that: the steel reinforced recycled concrete through the additional steel has increased the bearing capacity, the ductility and durability of the structure, and improved the seismic performance of concrete structure. Meanwhile, it achieves the recycling of construction waste so that achieve energy conservation and environmental protection.

(1)The mechanical performance of steel reinforced recycled mechanical properties with the ordinary steel reinforced concrete member concrete component similarity.

(2)Steel reinforced recycled concrete combination structure can not only make up for the deficiency of recycled concrete performance, and is beneficial to environmental protection, with ecological significance.

(3)Study on the steel reinforced recycled concrete structure is necessary, and there is still a lot of works to be done.

\section{Acknowledgement}

This research was financially supported by Shenyang scientific and technological projects (F14028200).

This research was financially supported by Shenyang scientific and technological projects (F13171900).

\section{References}

[1]Zhu Ying.Analysis and Research on the recycling of waste building concrete. Building gypsum and cementitious materials [J].New building materials, 2003(9): 57-59.

[2] BuckA D Concrete ofaggregate[J].ACI Journal,1997, 74(5): 212-219.

[3]Zhang Wei. Different substitution rate of steel reinforced concrete column regeneration compression experimental study [D].Chengdu: Xihua University, 2012.

[4]Guo Pengye.With different steel ratio of steel recycled experimental study on bearing performance of compressed concrete column [D]. Chengdu: Xihua University, 2012.

[5]Zhang Jie.Under low cyclic loading of steel recycled simulation numerical nonlinear analysis of concrete column[D].Xi'an: Xi'an University Of Architecture And Technology,2013.

[6]Xue Jianyang,Ma Hui.The steel recycled mechanical protection layer thickness of concrete column analysis[J].Engineering Mechanics. 2013, 30(5):202-206.

[7]Wang Yuncheng. Experimental study on compression ratio limit the ductility of concrete columns and the axis of the regeneration type steel [D].Xi'an: Xi'an University Of Architecture And Technology, 2013.

[8]Ma Hui. Study on the calculation method of steel recycled concrete columns in seismic performance and design[D]. Xi'an: Xi'an University Of Architecture And Technology,2013.

[9]Liao Xingnan. Finite element analysis of beams of steel recycled concrete[D]. Xi'an: Xi'an University Of Architecture And Technology, 2013.

[10]Xue Zhisheng. Experimental study on flexural performance of steel reinforced recycled concrete beams[D]. Chengdu: Xihua University, 2012.

[11]Xue Jianyang,Wang Xiuzhen.Experimental study on the performance of shear steel reinforced recycled concrete beam[J].Building structure.2013,43(7):69-72. 